\title{
E-Learning and Development of New Courses and Scientific Work in the Field of Pharmaceutical Technology
}

\author{
Hans Leuenberger ${ }^{\star a}$, Natalia Menshutina ${ }^{\mathrm{b}}$, Gabriele Betz ${ }^{\mathrm{a}}$, and Maxim N. Puchkova, b
}

\begin{abstract}
Since 2001, the Institute of Pharmaceutical Technology (IPT) at the University of Basel and the Mendeleyev University of Chemical Technology of Russia (MUCTR) have established an institutional partnership (IP), which is supported by the Swiss National Science Foundation (SNF) in the framework of the SCOPES (Scientific Cooperation between Eastern Europe and Switzerland) project. The results of this collaboration are the new teaching technologies that were introduced at the MUCTR and the IPT. The former include multimedia lectures in pharmaceutical technology, which are held in parallel at University of Basel and MUCTR, and the educational web-portal 'Pharmacy online', which was awarded a medal at the 4th Moscow International Salon of Innovations. The multimedia lectures are popular with and helpful for MUCTR students, because they can compensate to a certain extent the lack of equipment at the MUCTR. However, multimedia lectures can never replace hands-on training and therefore the continuation of the collaboration is ongoing. In this respect SNF decided in 2005 to give continuous support for this cooperation through the grant entitled 'New Concepts in Training Industrial Pharmacists and Pharmaceutical Engineers to Be Developed and Implemented at the Russian-Swiss Scientific and Education Centre in MUCTR'. This centre was established as a result of the previous grant. The development and implementation of a unique and innovative learning concept on the basis of the Russian-Swiss scientific and educational centre involving the Russian pharmaceutical and biotechnological industry, is an ongoing activity.
\end{abstract}

Keywords: Industrial pharmacist · e-learning · Learning Management System (LMS) · Pharmaceutical engineer · Pharmacy online $\cdot$ Russian-Swiss Science and Education Centre

\section{Introduction}

The IPT has developed an excellent teaching environment for both theoretical and practical university courses for pharmacy students. The diploma and Ph.D. students use state-of-the-art equipment and machinery for their studies due to an intensive collaboration of the IPT with the pharmaceutical industry.

\footnotetext{
${ }^{*}$ Correspondence: Prof. Dr. H. Leuenberger ${ }^{\mathrm{a}}$

Tel.: +41612671501

Fax: +41612671516

E-Mail: hans.leuenberger@unibas.ch

anstitute of Pharmaceutical Technology, University of

Basel

Klingelbergstrasse 50

Pharmazentrum

$\mathrm{CH}-4056$ Basel

www.pharmtech.unibas.ch

bepartment of Advanced Technologies

Mendeleyev University of Chemical Technology of

Russia

Miusskaya sq. 9

125047, Moscow

Russia
}

The IPT is working on the mechanistic understanding of drug formulation, on dosage form and process design and on drug delivery phenomena, and has established an excellent reputation worldwide.

In order to establish and integrate expert systems and computer-aided design into pharmaceutical technology, the expertise from computer scientists is needed. The Faculty of Process Cybernetics in Chemical Technology at MUCTR turned out to be an ideal partner for this task due to their expertise in chemical and information technology. The complementary skills of both partners (IPT and MUCTR) are a valuable combination and therefore contribute to the advancement of both universities in research and teaching.

\section{New Learning and Teaching Technologies at the IPT}

Three multimedia courses have been developed at the IPT, and are being used for Prof. Dr. H. Leuenberger's series of lectures: 'Solid Dosage Forms', 'Semi-solid Dosage Forms' and 'Liquid and Sterile
Dosage Forms'. Within the collaborative work with MUCTR, the material from these courses was translated into Russian and was used for the creation of multimedia education courses at the MUCTR. Thus the course entitled 'Technology and Equipment for Pharmaceutical Production' meets the requirements of the Pharmaceutical and Cosmetic Technology Department at MUCTR, and is now being used for teaching students of this department.

Multimedia mathematical model equations module 'PhysPharm' was designed and developed at the IPT. PhysPharm is an index of basic mathematical formulae used in pharmaceutical technology. However, PhysPharm is not just a static collection of information: It is also an interactive Javabased education tool that allows students to study the behaviour of the physicochemical systems in silico by entering the required parameters and watching the animated response. Such a tool allows the students to 'feel' the response of a real system and to further understand the physical basics of pharmaceutical technology (Fig. 1).

The system that binds together the heterogeneous learning media like Pow- 


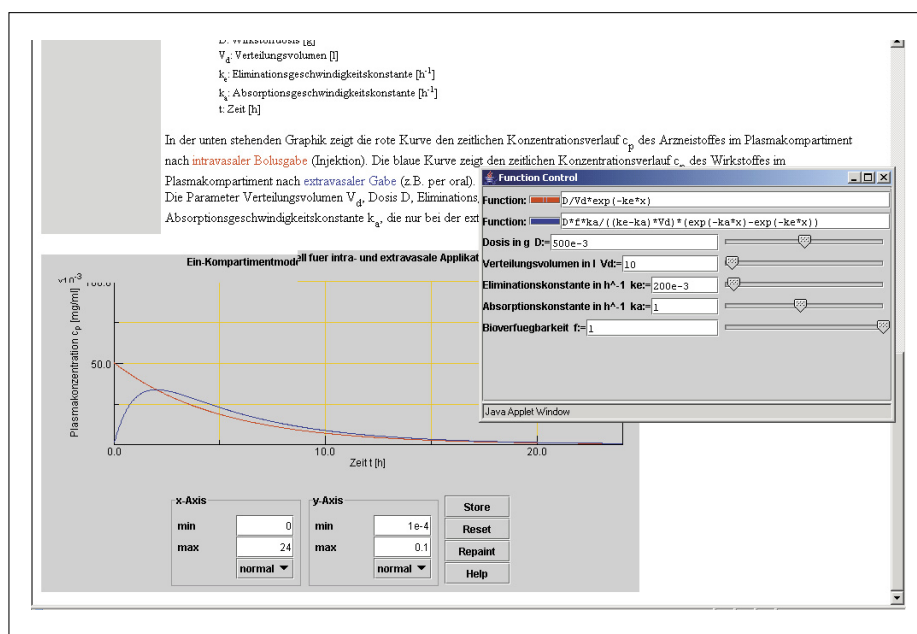

Fig. 1. Screenshot of PhysPharm browser window

erPoint ${ }^{\circledR}$ slides, PhysPharm modules and interactive questionnaires is a learning management system (LMS). Such an LMS was developed at the IPT, and is based on PHP/MySQL/XOOPS software. This LMS provides powerful capabilities for course content management, by tracking students' activities and progress. An important part of this LMS is a testing system based on Macromedia Flash MX quiz template with the following six interaction types:

- True or False (requires the students to select the correct answer)

- Fill in the Blank (requires the students to type in the answer)

- Multiple Choice (requires the students to select one or more answers)

- Drag and Drop (requires the students to arrange the objects in the correct order)

- Hot Object (requires the students to select the answer by clicking the object(s))

- Hot Spot (requires the students to spot the area on a picture or diagram)

The students' responses are logged by the LMS database and are displayed after completing the test (Fig. 2).

This helps students to have a clear view of the course 'backbone', and guides them to a better understanding of the key points in the theoretical and practical course material.

At the MUCTR the specialized LMS, based on the Claroline LMS engine, was developed. Claroline has the same basic features as WebCT and they are both compatible. Since February 2003, the developed elearning portal 'Pharmacy online' based on the Claroline learning management system, was filled with content, and has opened for student access within the MUCTR network (Fig. 3). In 2004 the web-portal 'Pharmacy online' was awarded a medal at the 4th Moscow International Salon of Innovations (Fig. 4).

Furthermore, multimedia module 'PhysPharm' and multimedia lectures

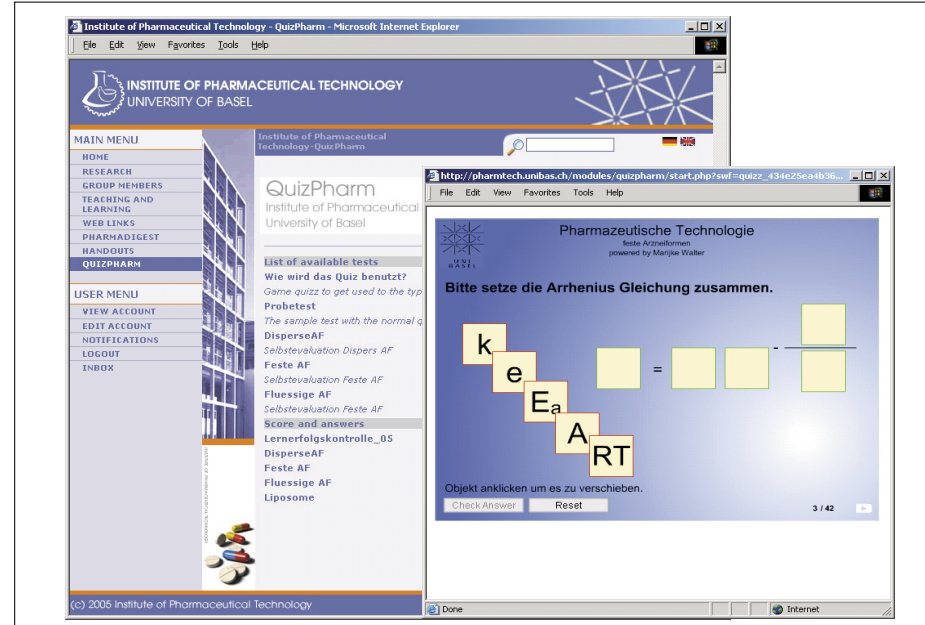

Fig. 2. Screenshot of the testing system of the IPT ('Drag and Drop' interaction)

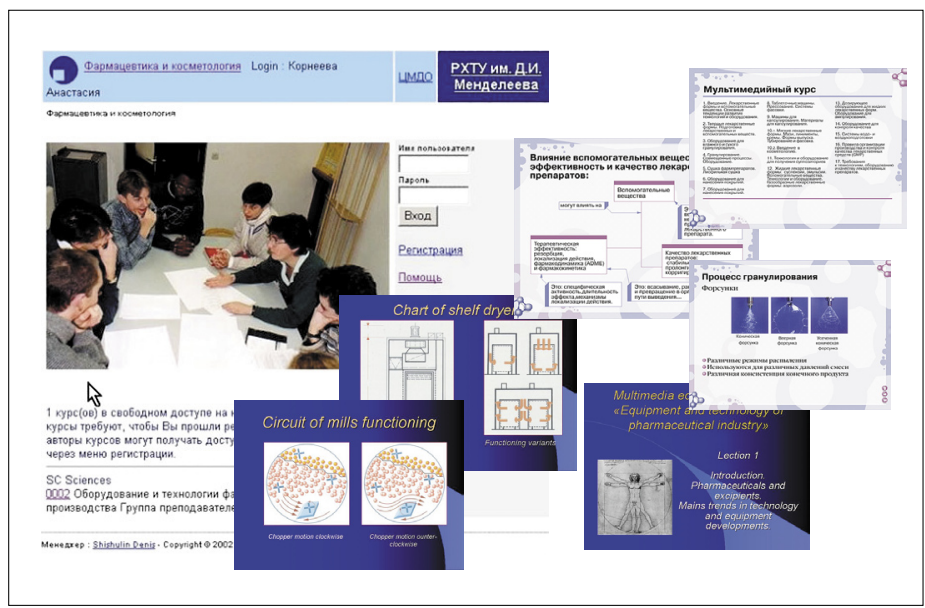

Fig. 3. Screenshot of Claroline-based e-learning portal 'Pharmacy online'

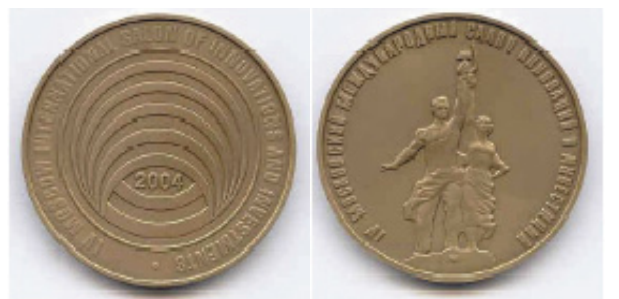

Fig. 4. Medal awarded to 'Pharmacy online' at the $4^{\text {th }}$ Moscow International Salon of Innovations (Moscow, Russia)

'Solid Dosage Forms', 'Semi-solid Dosage Forms' and 'Liquid Sterile Dosage Forms' were translated from German into Russian, whereas the multimedia course 'Technology and Equipment for Pharmaceutical Production', developed at the MUCTR, was translated from Russian into English.

The compatibility of internal structures of both LMS web-platforms gives an opportunity to create standards in education and to create multimedia education environments.

Created education environments can be tuned to meet different requirements, such as raising the level of engineer skills, etc. by applying different modules. Some of these modules are mentioned below.

First, a virtual lab-training environment is being developed on a Case-Based Reasoning (CBR) technology with a combination of artificial neural network packages and learning management system, and allows experimental and theoretical data knowledge acquisition and storage within the expert system knowledge database. The latter is accessible as a training and scientific tool.

The second possibility is mathematical modelling and study of different processes, for example, freeze-drying. This technology could find a wide range of applications, e.g. in nano-science, pharmaceutical technology, and food industry [1].

The production of nano-composites using the spray-freeze-drying technique is a project intended to design new spray-freezedrying equipment. Atmospheric freeze-drying of spray-frozen particles is a process that eliminates the typical problems of classical freeze-drying. The advantages are product form and structure control, shorter process 
times, and absence of problems associated with the generation and maintenance of a vacuum [2].

\section{Russian-Swiss Science and Education Center for Pharmaceutical and Biotechnologies}

As the result of an institutional partnership between the IPT and the MUCTR, the Russian-Swiss Education and Scientific Centre for pharmaceutical and biotechnologies has been established at the MUCTR (Fig. 5). This centre is a new platform designed to enhance Russian-Swiss relations in education, science and technology. The centre is headed by Prof. N. Menshutina, as executive director, and is supported by Prof. $\mathrm{H}$. Leuenberger, as honorary director. The main activities of the Centre are:

- To guarantee the legal assistance for domestic and/or international technology transfer;

- To provide technical support for science-intensive projects;

- Development of a domestic and/or international information exchange network with the focus on pharmaceutical and bio-technologies;

- Carrying out research at the centre's technological facilities upon demand from clients;

- Organization of technology transfer seminars;

- Monitoring the intellectual property market in the field of pharmaceutics and biotechnology, and distributing the market analysis within the target group;

- Organization of domestic and/or international conferences for leading specialists and official representatives of governmental institutions;

- Development and implementation of special-purpose study courses for MUCTR students;

- Providing the special training for students and personnel of the centre's client organizations;

- Organizing the extension and retraining courses for specialists in the field of pharmaceutical and biotechnologies;

- Information systems development for international technology transfer centres with Russian participation.

\section{Outlook: SCOPES 2005-2008}

It is an important issue that SNF has decided to give continuous support for this collaboration through the grant entitled 'New Concepts in Training Industrial Pharmacists and Pharmaceutical Engineers to Be Developed and Implemented at the Russian-Swiss Scientific and Education Centre

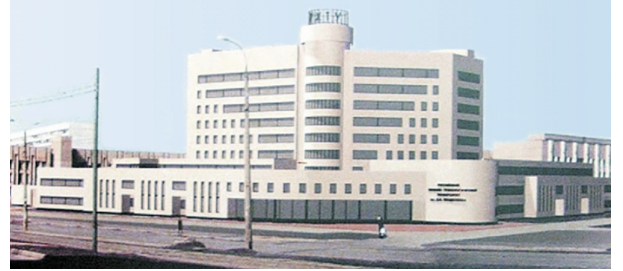

Fig. 5. Computer simulation of the building planned to be ready in 2006 in the northern High-Tech Park of MUCTR, with space for the Russian-Swiss Scientific and Educational Centre in Moscow

in MUCTR'. This grant is a continuation of the SCOPES 2001-2004 program entitled 'Development of New Courses and Scientific Work in the field of scientific education'. As cited from the SNF brochure 'Scientific cooperation with Eastern Europe: A Swiss contribution to the countries in transition [3], this collaboration has built a platform to transfer high-level Swiss experience at training pharmacists to Eastern Europe:

"Like Manen, Hans Leuenberger from the Institute of Pharmaceutical Technology at the University of Basel has met scientists in Moscow who have tremendous faith in the future. Leuenberger, a physicist and pharmacist, and his research partner $\mathrm{Na}$ talia Menshutina, an expert in informatics from the Mendelev University of Chemical Technology of Russia, have been engaged in interdisciplinary collaboration for years. "Disciplines like the nanosciences and system[s] biology show that sciences such as biology, chemistry and physics are increasingly merging with information technology," Leuenberger explains, adding, "in research, including pharmaceutics, modelling and computer simulation are becoming more important all the time". Leuenberger and his team have learned a lot from their Russian colleagues about artificial intelligence, artificial neuronal networks and database management. Together, the scientists have developed an e-based learning and expert system in pharmaceutical technology that is now in use in both Basel and Moscow. "We were especially pleased that the Russian Ministry of Research and Technology awarded us a prize for this e-learning platform," Leuenberger says. "Multimedia teaching modules and e-platforms for distance learning have great potential," Menshutina adds. "In a country as big as Russia, we need to be able to access electronic teaching materials simultaneously from Kaliningrad to Vladivostok." Collaboration thrives on differences. Many scientists in Switzerland are impressed by the talent for improvisation demonstrated by their colleagues from Eastern Europe. "Necessity is the mother of invention," Leuenberger says, "but this is less evident in contemporary Switzerland because our country has reached a saturation state in which inaction is not uncommon".

Since the Bologna agreement was signed, the University of Basel has invested great deal of effort in the reorganization and improvement of the study programs. Thus, the department of pharmacy has also introduced the Bachelor of Science degree in 2003, and will introduce the Master of Science degree in 2006. According to the Bologna agreement the study program is organized in learning modules, and can be tailored to the students' preferences. Therefore a modular-based program of Master of Industrial Pharmacy and Pharmaceutical Engineering is currently being developed at the IPT.

Common training modules are planned in Business and Administration, Soft Skills, Quality Management (QM), Knowledge Testing and Engineering Basics. Thus, the two education directions have the possibility to meet each other during the study program and have the same knowledge base to communicate.

The described SCOPES project will boost the Russian industry in the area of pharmaceutics and biotechnology. Up to now a training scheme for industrial pharmacists and pharmaceutical engineers did not exist, and the industry was employing pharmacists that were trained for retail pharmacy shops. This situation was unsatisfactory for both sides. By introducing the master programs, according to the Bologna agreement, and establishing the learning modules according to the needs of the industry, the graduate students have an excellent future.

Received: December 22, 2005

[1] A. Martin, 'Physikalische Pharmazie', Ed. H. Leuenberger, Stuttgart: Wiss. Verl. Ges., 2002.

[2] M. Mumenthaler, H. Leuenberger, Int. J. Pharm. 1991, 72, 9 .

[3] H. Leuenberger, J. Nanop. Res. 2002, 4, 111.

[4] R. Lässig, I. Seidl, A. Stark, S. Hille, E. Glättli, J. Pfister, 'Scientific cooperation with Eastern Europe: A Swiss contribution to the countries in transition', Swiss National Science Foundation, 2005. 